\title{
THE VIEW FROM ABOVE: A DRONE'S PERSPECTIVE ON THE WORLD
}

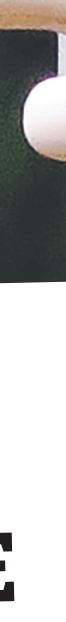




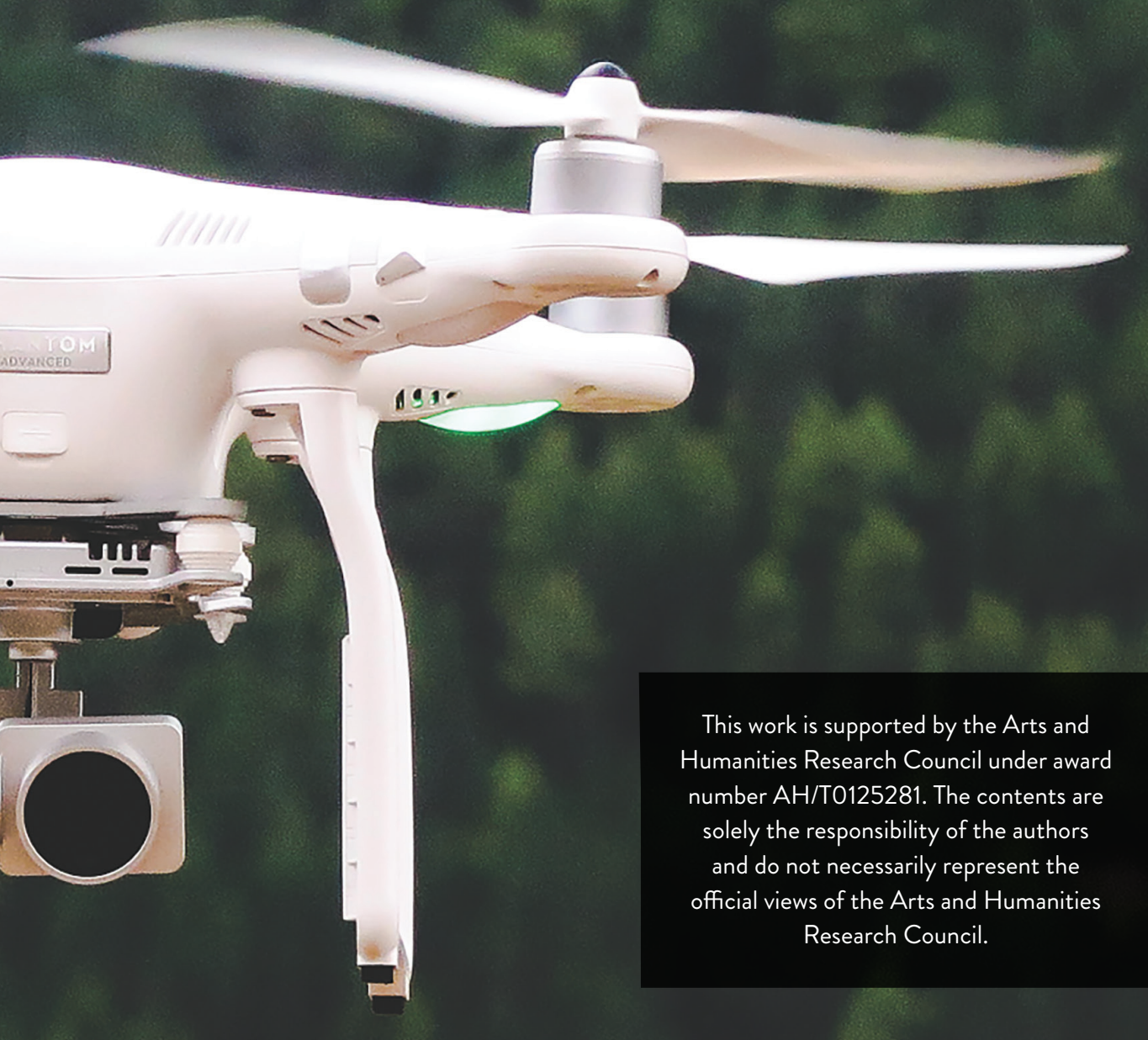

shadows change your experience of the image?' and 'What emotions does this image make you feel?'

"All comments and survey responses will be subjected to thematic analysis to tease out key topics related to people's opinions of drones," says Elisa, "whether in terms of the composition of visuals, the feelings they generate, or broader reflections on drones and the view from above."

\section{PERCEPTIONS OF DRONE VISUALS}

Survey responses so far have suggested that drone visuals can challenge people's current understanding of drones and drone photography. "Many members of the public expressed surprise that drones can be used artistically to create abstract art and that they were increasingly owned by "ordinary people', not just techies or the military," says Lauren. "However, many viewers felt that drones could never replace traditional landscape photography as most users are pilots first and photographers second."

Survey participants have commented that drone images can offer new perspectives on the world, as drones provide a viewpoint that is not accessible to us on the ground. Quoted advantages of drone photography over traditional aerial photography (conducted from a plane) include how drones are more eco-friendly and socially alternative for amateur photographers.

"Drawing attention to how drones are used in everyday life for photography definitely came as a positive surprise to many members of the public who still associated their usage with warfare and surveillance, and they openly understanding of drones," explains Lauren. "While this is great from the perspective of our research, we must be careful not to down-play people's persisting concerns around drones."

Understandably, some respondents remained concerned about issues of drone surveillance and privacy. It would feel very intrusive to have a drone buzzing overhead if you were sitting in your garden or enjoying a day at the beach, knowing that it has the potential to be filming you from above. And while drones are reasonably quiet, noise was another concern raised by participants as the buzzing hum of a drone can spoil a peaceful landscape.

Elisa and Lauren are keen to emphasise they are not trying to create a utopian image of drones or deny that the view from above can be problematic, but they do hope to encourage people to reflect more critically on their artistic, aesthetic, social, cultural, historical and political connotations. Their digital exhibition should be seen as a springboard to open a dialogue on the topic. Museums and art inclusive, providing a greener and cheaper stated that it had made them rethink their

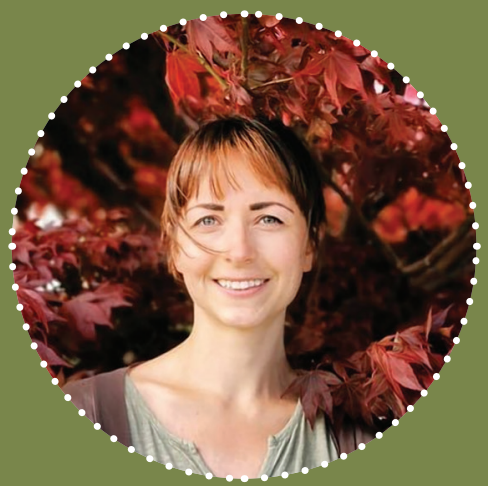

DR ELISA SERAFINELLI

Research Fellow, Department of Sociological Studies, University of Sheffield, UK

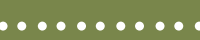

\section{FIELDS OF RESEARCH}

Digital Media, Media and Communication, Visual Studies

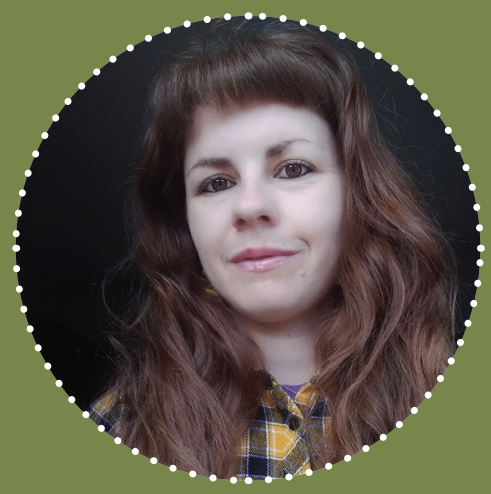

\section{DR LAUREN ALEX O'HAGAN}

Research Associate, Department of Sociological Studies, University of Sheffield, UK

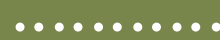

\section{FIELDS OF RESEARCH}

Victorian and Edwardian Material Culture, Media and Communication,

Visual Studies

..........

\section{RESEARCH PROJECT}

Investigating public perceptions of drone visuals

..........

\section{FUNDER}

Arts and Humanities Research Council (AHRC)

galleries can also contribute to normalising the use of drones by exhibiting drone photographs.

Hopefully, Elisa and Lauren's research will help the public to appreciate the new and creative ways in which drones can operate and showcase the unique perspectives of our world that they can capture. 


\section{ABOUT VISUAL, CULTURAL AND DIGITAL MEDIA STUDIES}

Elisa and Lauren's research is multidisciplinary, spanning the fields of visual, cultural and digital media studies. The field of visual studies is concerned with how visual artefacts are used and understood, while cultural studies focuses on everyday practices of life and how cultures are constructed and evolve. Digital media studies investigates how digital content is created and used and how it impacts society.

"When combined, all three disciplines offer a complementary way of exploring how our social, cultural and political worlds are shaped by media technologies," explains Elisa. "This multidisciplinary approach enables us to identify the motivations behind drone visuals and their sociocultural effects. In addition, we investigate how technological developments influence our visions, practices and understanding of the space in which we live."

\section{VISUAL COMMUNICATION IN A}

\section{DIGITAL SOCIETY}

"Visual communication has always been an essential part of human communication," says Elisa. If a picture is worth a thousand words, then it is no wonder that we rely so heavily on images. But, in an increasingly digital society, our methods for producing and distributing visual artefacts are rapidly changing, as is the way we interpret visual information. A picture is no longer a canvas masterpiece painted over several weeks, to be hung in a grand house. Today, a picture is a moment snapped by a smartphone and instantly shared with the world.

"The internet has increased interactivity and connectedness like never before," says Elisa. "The expansion of social media, smartphones, artificial intelligence and virtual reality has altered the way we interact by extending options for unique visual communication."

\section{APPRECIATING DRONE VISUALS}

Lauren finds studying drone visuals to be a real pleasure (and looking at the photos exhibited for the project, it is easy to see why). Photographs have a way of transporting the viewer to the place in the image. When admiring drone images, you can travel to a Buddhist temple in Thailand or a snowy mountain pass in Switzerland from the comfort of your own home.

"The more you look at an image, the more subtle things you begin to notice in terms of framing, angle or the use of light and shade," says Lauren. "I find it extremely rewarding when sharing these findings with others leads to positive feedback or opens a debate about different aspects of drone photography. It means that all of our research has been worthwhile."

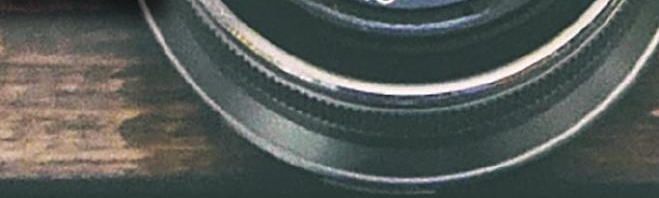

\section{EXPLORE A CAREER IN VISUAL, CULTURAL OR DIGITAL MEDIA STUDIES}

- With a degree in visual, cultural or digital media studies, you could be a photographer, graphic designer, journalist or art consultant. You could find yourself working in an advertising firm, for a publishing company, on a film set, as a social media manager or at a museum. Or you could become an academic like Elisa and Lauren.

Elisa advises broadening your knowledge of visual culture by joining local clubs that teach activities such as photography, art or computing. She also suggests trying to find work experience in journalism, social media or communication agencies.

Explore the resources from organisations such as the Association of Internet Researchers (www.aoir.org), the International Association for Media and Communication Research (www.iamcr.org) or the European Communication Research and Education Association (www.ecrea.eu) to learn more about the topics studied by visual, cultural and digital media researchers.

Prospects has information about what you can do with a degree in media studies: www.prospects.ac.uk/careers-advice/what-can-i-do-with-my-degree/media-studies

\section{PATHWAY FROM SCHOOL TO VISUAL, CULTURAL OR DIGITAL MEDIA STUDIES}

The interdisciplinary nature of visual, cultural and digital media studies means many subjects are beneficial if you want to pursue a career in these fields. "Studying

English, history, art, photography or sociology at school or college would provide

a good grounding in forms of human communication, as well as how society has been (re)shaped by communication

throughout history," says Lauren.

Many universities offer degrees in visual culture, digital media, media studies, art history, and language and communication. "Any of these would provide an excellent foundation for someone wishing to study and research visual culture or digital media practices as a career," says Lauren.

\section{ELISA AND LAUREN'S TOP TIPS}

OI Have an intellectual curiosity and be attentive to the world around you.

02 Going abroad to study or work will broaden your horizons and heighten your ambitions.

03 Don't take everything you read or see at face value - think about the deeper meanings and agendas behind it. This will help you develop many important skills that will be useful as a researcher.

$G$

(5)

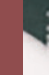




\section{MEET DR ELISA SERAFINELLI}

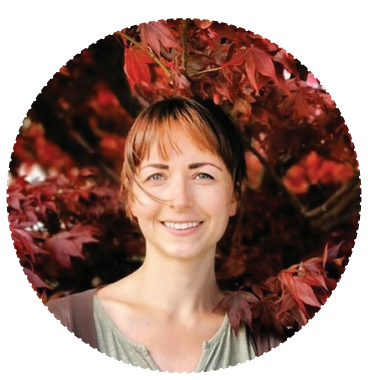

When I was younger, I enjoyed photography and painting. I was also interested in visual communication and the history of art. For my PhD, I explored how Instagram changed people's visual experiences and online social practices. As a result of this work, I published a book titled Digital Life on Instagram and wrote several academic journal articles. Publishing this book is one of the highlights of my career so far.

I am currently the co-director of the Digital Society Network at the University of Sheffield. We are a loose network of researchers within the Faculty of Social Sciences, examining all aspects of digital- society relations. We aim to stimulate and support research into our digital society.

My ambition is to become a leader in the field of visual mobile communication in the digital age. I hope to bring visual communication and cultural studies researchers into conversation with other fields, especially internet, digital and mobile media studies.

In my free time, I enjoy doing sports and outdoor activities. I also like travelling and baking, and I still retain my interest in photography and painting.

\section{MEET DR LAUREN ALEX O'HAGAN}

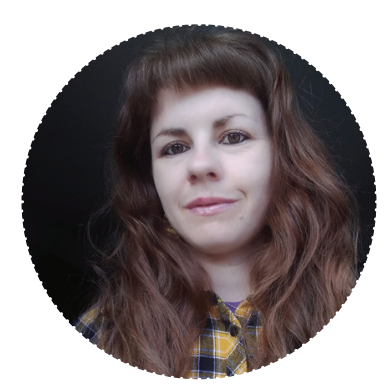

I have quite an eclectic research background! But all my projects have been grounded in visual culture and are concerned with the ways in which a particular visual artefact communicates ideas.

My PhD focused on Edwardian book inscriptions and what they reveal about social class in early 20th century Britain. After my PhD, I became interested in exploring broader Edwardian visual culture and its overlap with socio-political issues, so I turned my attention to propaganda postcards.

I was interested in how postcards were used to promote political messages to the public using a combination of words, images, colour and typography. I studied political postcards related to the women's suffrage movement and the Irish campaign for Home Rule. At the same time, I also developed an interest in Victorian and Edwardian food and drink advertisements and the ways in which science was used to promote certain products.

More recently, I have investigated rock memorabilia, particularly tour t-shirts and battle jackets (denim cut-offs with patches worn by heavy metal fans). Using a combination of visual analysis and interviews, I have explored how their designs enable fans to signal individual and collective identity.

My greatest career highlight to date was the opportunity to work as a visiting scholar at Örebro University in Sweden after finishing my PhD. I was invited there by Professor David Machin, a leading academic in my field whose work I greatly admire. I am thrilled to be returning to Örebro in 2022 to take up a postdoctoral researcher role, where I will continue my research on the use of science in early 20th century food and drink advertising, but this time in a Swedish context.

Music is my biggest passion - I play bass guitar, go to live gigs and run an Instagram fan page for my two favourite musicians. I also love reading, learning foreign languages, travelling, swimming and playing squash. 